\title{
Caractérisation socio-économique des grands bassins de productions d'anacardiers (Anacardium occidentale) et étude comportementale de leur peuplement dans le Cameroun septentrional
}

\author{
Bourou SALI ${ }^{1}$, Chantal MADOU ${ }^{2 *}$, Abraham NOME $^{3}$ et Jean KUATE ${ }^{4}$ \\ ${ }^{1}$ Institut de Recherche Agricole pour le Développement (IRAD) de Garoua Station polyvalente de Recherche \\ de Garoua (Nord Cameroun). B.P. : 415 Garoua, Cameroun. \\ ${ }^{2}$ Institut de Recherche Agricole pour le Développement (IRAD) de Yaoundé Centre de Recherche de Yaoundé \\ (Littorale Cameroun). B.P. : 2067 Yaoundé, Cameroun. \\ ${ }^{3}$ Institut de Recherche Agricole pour le Développement (IRAD) de Ngaoundéré Centre de Recherche de \\ wakwa (Adamaoua Cameroun). B.P. : 65 Ngaoundéré, Cameroun. \\ ${ }^{4}$ Institut de Recherche Agricole pour le Développement (IRAD). Direction Générale. B.P. 2123 Yaoundé, \\ Cameroun. \\ *Auteur correspondant ; E-mail : chantal.madou@yahoo.fr
}

\section{REMERCIEMENTS}

Les auteurs remercient la SODECOTON (Société de Développement du Coton du Cameroun) en partenariat avec l'IRAD (Institut de Recherche Agricole pour le Développement) et le CIRAD (Centre international de Recherche Agronomique pour le Développement), pour le financement accordé à la réalisation de ce travail.

\section{RESUME}

Le système agroforestier à base d'anacardier est très dynamique mais fortement influencé par plusieurs facteurs sociaux dont l'importance varie d'une zone à une autre. Cependant, depuis leur mise en place, peu d'informations existent sur la situation de la ressource. L'objectif de cette étude est d'analyser la situation actuelle des plantations d'anacardiers dans les principales zones de production du Cameroun septentrional. Les données relatives aux caractéristiques socio-économiques des producteurs d'anacarde ont été collectées dans le Cameroun septentrional à l'aide d'un questionnaire. Il ressort de cette enquête que 98,04\% des planteurs d'anacardier sont des hommes contre seulement $1,96 \%$ pour les femmes. Une proportion de $68,63 \%$ des enquêtés déclarent avoir des superficies de champs comprises entre 0 et 0,5 ha, seulement 3,922\% ont 10 ha et plus. Les activités liées à la filière anacarde est rentable pour les enquêtés $(90,2 \%)$. Le test ANOVA, des données dendrométriques révèle des différences significatives du diamètre au collet $(\mathrm{P}=0,000)$, du DHP $(\mathrm{P}=0,000001)$ et de la hauteur $(\mathrm{P}=0,000484)$ entre les différentes zones étudiées. Le test ANOVA ne révèle aucune différence significative $(\mathrm{P}=0,24)$ du recouvrement entre les zones. Toutefois, une valorisation de la filière par le gouvernement permettra aux producteurs d'améliorer considérablement leurs plantations et par conséquent, le niveau de revenu des producteurs.

(C) 2020 International Formulae Group. All rights reserved.

Mots clés : Caractéristique, culturale, producteur, anacarde, septentrional. 


\title{
Socio-economic characterization of the large cashew production basins (Anacardium Occidentale) and behavioral study of their populations in Northern Cameroon
}

\begin{abstract}
The cashew-based agroforestry system is very dynamic but strongly influenced by several social factors those importance varies from one area to another. However, since their establishment, few information exists on the situation of the resource. The objective of this study is to analyze the current situation of cashew plantations in the main production areas of northern Cameroon. Data relating to the socio-economic characteristics of cashew producers were collected in northern Cameroon using a questionnaire. This survey shows that $98.04 \%$ of cashew planters are men compared to only $1.96 \%$ for women. A proportion of $68.63 \%$ of the interviewed declared that they had areas of fields between 0 and 0.5 ha, only $3.922 \%$ had 10 ha and more. The activities linked to the cashew sector is profitable for the farmers $(90.2 \%)$. The ANOVA test of dendrometry data, reveals significant differences in the diameter at the neck $(\mathrm{P}=0.000)$, the DHP $(\mathrm{P}=$ $0.000001)$ and the height $(\mathrm{P}=0.000484)$ between the different areas studied. The ANOVA test reveals no significant difference $(\mathrm{P}=0.24)$ in the overlap between the zones. Taking these factors into account will allow sustainable management of the system. the government's supply chain will allow producers to significantly improve their plantations and therefore the level of income generated of producers.
\end{abstract}

(C) 2020 International Formulae Group. All rights reserved.

Keywords: Characteristic, cultural, producers, cashew, Northern.

\section{INTRODUCTION}

L'anacardier, Anacardium occidentale L., appartient à la famille des anacardiacées. Il serait originaire des régions tropicales du Brésil (Trevian et al., 2005). C'est un arbre qui peut atteindre une dizaine de mètres et dont le diamètre du tronc peut varier entre 1,2 à $1,5 \mathrm{~m}$ (Lautié et al., 2001). Du point de vue pédologique, l'anacardier est une plante qui s'adapte à une large gamme de sols, notamment les sols légers, sableux, profonds et bien drainés, d'où son caractère rustique (Olossoumaï et Agbodja, 2001). Outre les fruits que sont la noix et la pomme de cajou, la plante fournit une gamme de produits secondaires. La noix de cajou au sens botanique du terme, est le vrai fruit de l'anacardier. C'est un akène de couleur grise ou brun gris à maturité, réniforme et mesurant en moyenne $2,7 \mathrm{~cm}$ de long sur $2,1 \mathrm{~cm}$ de large et 1,6 cm d'épaisseur (Lautié et al., 2001). L'anacardier est un fruitier dont la culture contribue au développement socioéconomique de plusieurs pays du monde (De figueiredo et al., 2001 ; Marlos et al., 2007). La noix qui est le principal produit commercial (Lacroix, 2003) est utilisée dans plusieurs domaines dont l'agroalimentaire, le cosmétique, la médecine et l'industrie automobile (Soro, 2012 ; Aliyu et Awopetu, 2007). Il est aujourd'hui largement cultivé dans toutes les zones tropicales, comme en Afrique, aux Antilles, au Brésil, en Asie du Sud-Est et en Inde. Anacardium occidentale L. a été introduit en Afrique par les navigateurs portugais vers le 15éme siècle comme plante d'agrément et pour fixer les dunes (Tandjiekpon, 2005). Il participe aussi à la conservation de la biodiversité et à la reconstitution des terres de culture dégradées et appauvries. Depuis 2015, la Côte-d'Ivoire est devenue le premier pays producteur et exportateur mondial de noix de cajou avec plus de 700 mille tonnes devançant ainsi l'Inde, le Vietnam et le Brésil (Kouassi et al., 2018). Le Cameroun n'est pas cité parmi ces pays producteurs en Afrique bien que connu. Cependant sa culture est seulement propice aux trois régions septentrionales du pays à savoir l'Adamaoua, le Nord et l'Extrêmenord. Actuellement, suite à la demande grandissante, sa culture s'étend à d'autres 
régions telles que l'Est et le Centre du pays (Hamawa et al., 2019). De nos jours, l'anacardier est une culture de rente en plein essor et représente pour l'Afrique une grande opportunité à travers l'exportation de ses noix (Dedehou et al., 2015). Sa production mondiale a presque doublé en moins d'une décennie, passant de 2361384 tonnes en 2002 à 4152315 tonnes en 2012 (FAO, 2014). Malgré l'énorme potentiel de revenus financiers issus de la vente des noix d'anacarde sur le plan mondial (FAO, 2014), au Cameroun, la production de noix de cajou demeure encore très faible (Hamawa et al., 2019). Actuellement, il existe un document relatif à la «Stratégie nationale de développement des chaînes de valeurs de la filière anacarde au Cameroun 2019 - 2023 » qui met en exergue les potentialités du Cameroun à produire et exporter les noix de cajou. C'est pourquoi, la SODECOTON (Société de Développement du Coton du Cameroun) en partenariat de longue date avec l'IRAD (Institut de Recherche Agricole pour le Développement) et avec le CIRAD (Centre international de Recherche Agronomique pour le Développement), ont décidé principalement de lui accorder dès lors un intérêt particulier. L'objectif général de cette étude est la caractérisation socio-économique des producteurs, les performances et les contraintes de gestion des plantations d'anacardiers. Plus spécifiquement il est question de :

> Générer des connaissances sur les zones de production (superficie des plantations, utilisation des intrants agricoles, période de récolte, âge des plantations, etc...).

$>$ Contribuer à la connaissance de la variabilité interspécifique des plantations (paramètres dendrométriques).

\section{MATERIEL ET METHODES}

\section{Site d'étude}

La présente étude a été conduite dans les deux zones agro-écologiques (la zone Soudano sahélienne et la zone des hautes savanes guinéennes) favorables à la culture de l'anacardier au Cameroun. Dans la zone
Soudano sahélienne, il y a deux saisons (sèche et humide) (Ndong et al., 2015) et plus au Nord le climat est de type tropical sec caractérisé par au moins sept mois de sécheresse. Les précipitations annuelles variant de 500 à $1600 \mathrm{~mm}$, certaines années, la pluviométrie atteint difficilement 100 jours. On observe une variation de la Période de Croissance Végétale (PCV) en fonction de ces pluies. Dans la zone des hautes savanes guinéennes où il pleut plus longtemps, cette période est plus longue et peut atteindre 250 jours (Manetsa et al., 2011). Les travaux présentés sont issus d'une enquête menée durant la période allant de juillet 2018 à novembre 2018 dans les départements du Mayo Rey (Touboro), de la Bénoué (Garoua $3^{\text {ème}}$ ), de la vina (Ngaoundéré $3^{\text {ème }}$ ) et du Mayo-Danay (Yagoua) auprès des propriétaires d'anacardiers (Figure 1).

\section{Collecte des données}

La collecte des données s'est faite au moyen des enquêtes et des observations enregistrées dans une fiche d'enquête. Les enquêtes ont été menées auprès des populations ayant des champs d'anacardes et les responsables des institutions publiques ou privées de la zone d'étude. Deux types de questionnaires ont été préparés pour chacune des catégories des enquêtés à savoir les producteurs et responsables des institutions en charge. Les observations quant à elles ont été faites sur les différents sites indiqués, ce qui a permis d'apprécier la qualité des plantations. Les paramètres quantitatifs déterminés ont concerné :

- Le nombre de femmes et d'hommes ayant des plantations d'anacardiers ;

-L'âge des producteurs de cajou ;

- L'âge moyen des plantations d'anacardier ;

- La superficie des parcelles exprimée en ha et la densité de plantation ;

-La profession des producteurs et la rentabilité de l'activité ;

-Le circuit de commercialisation des noix ;

-La fertilisation et le traitement phytosanitaire des plantations ; 
-Les cultures associées à celle de l'anacardier ;

- les périodes de récolte des noix ;

L'identification et la caractérisation des différentes plantes d'anacardes a été faite en fonction des grands bassins de production et des champs existants. Cette démarche a permis de mesurer les paramètres dendrométriques suivants :

- Diamètre au collet ;

- $\quad$ Diamètre à hauteur de poitrine $(1,3 \mathrm{~m})$;

- Hauteur ;

- $\quad$ Surface de recouvrement ;

- $\quad$ Longueur de la feuille ;

- $\quad$ Largeur de la feuille.

L'ensemble de ces paramètres a été pris à l'aide d'un décamètre, excepté la hauteur qui a été mesurée à l'aide d'un clinomètre.

\section{Analyse statistique}

Les données d'enquêtes ont été dépouillées sur IBM SPSS Statistics20, Google drive et Microsoft Excel. Ces données ont permis de réaliser des histogrammes expliquant la distribution des paramètres quantitatifs sous évoqués. Les données issues des paramètres dendrométriques ont été soumises à une analyse de variance (ANOVA) suivie du test de séparation des moyennes de Turkey au seuil de $5 \%$ à l'aide du logiciel Statistica version 8.0.

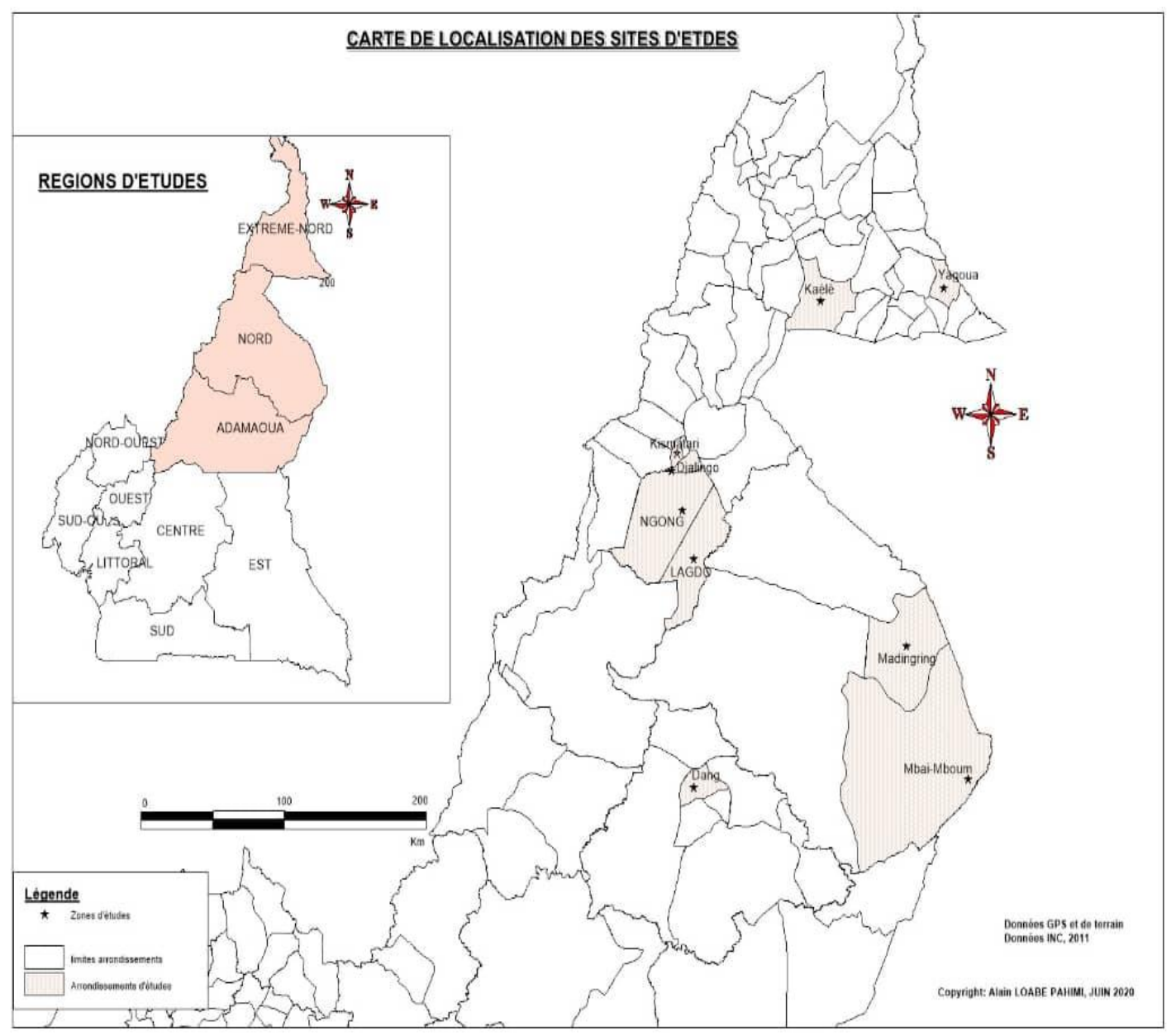

Figure 1 : Carte de localisation des sites d'études. 


\section{RESULTATS \\ Caractérisation des producteurs d'anacardiers}

En ce qui concerne le sexe, les données recueillies montrent que les hommes sont plus détenteurs d'anacardiers que les femmes. En effet, pour toutes les zones d'étude, 98,04\% des planteurs ou détenteurs de plantations d'anacardier sont des hommes contre seulement $1,96 \%$ pour les femmes (Figure 2a). De façon globale, il est observé que les populations productrices ou détentrices des plantations d'anacardier sont relativement vieilles, quelque soit la zone concernée. Les tranches d'âges intéressées à la culture de l'anacardier dans les zones étudiées sont comprises entre 15 et 55 ans+. La culture d'anacardiers est répandue chez toutes les classes d'âge avec prédominance des personnes d'âge de 55 ans-Plus $(45,1 \%)$. Les personnes de classe d'âges comprises entre 45 et 55 ans $(21,57 \%)$, de $35-45$ ans $(19,65 \%)$ et de moins de 25 ans $(15,69 \%$ ) (Figure 2b).

\section{Profession des personnes exerçant cette activité dans la zone d'étude}

D'après l'enquête réalisée, $70,59 \%$ de la population étudiée sont agriculteurs. Pendant que $7,84 \%$ sont des retraités, 3,92\% sont des fonctionnaires et des commerçants, $1,91 \%$ sont des étudiants et les autres exercent diverses activités avec un pourcentage égal à $11,76 \%$ (Figure 3).

\section{Superficie des champs des enquêtés}

Les sondages effectués auprès des populations des zones d'études montrent que les acteurs de la filière anacarde n'ont pas de grandes parcelles dédiées à cette activité. Soit, $68,63 \%$ des enquêtés déclarent avoir des superficies de champs comprises entre 0 et 0,5 ha (Figure 4), seulement $3,922 \%$ ont 10 ha et plus. Dans ces superficies, le nombre d'arbres varie entre $1-10$ pieds $(33,33 \%)$ et 101 et plus $(19,61 \%)$. Toutefois, les plantations d'anacardier ont tendance à augmenter ces trois dernières (2017-2020) avec l'intérêt des pouvoirs publics, de la recherche et des producteurs.

\section{Densité d'arbre dans les champs d'anacardes}

La plus grande exploitation est de 460 ha recouvert par 12000 plants d'anacardier. Cette plantation retrouvée dans le département de la Bénoué et plus précisément dans l'arrondissement de Garoua $3^{\text {ème }}$ est la plus vaste du pays. Le reste des densités varie entre 19 et 198 pieds pour 0,25 à 10 ha de superficie. La densité prescrite par la recherche de 100 plants à l'hectare n'est respectée sur aucun site ceci à cause des cultures en association que pratiquent les enquêtés dans leurs champs (Figure 5). Cette tendance de densité moins forte est surtout observée au niveau des plantations moins âgées réalisées au cours de ces quinze dernières années qui coïncident aussi avec la période où l'anacardier a commencé par prendre de l'importance dans les systèmes d'exploitation agricoles du pays.

\section{Diversité d'accession d'anacardes produites dans les exploitations d'anacardes}

La Figure 6 met en évidence la diversité des accessions d'anacardes produites dans les plantations d'anacardier. Il est clair que trois accessions sont régulièrement évoquées par les enquêtés. Celle de couleur jaune qui prédomine $(74,51 \%)$, suivie du rouge $(15,69 \%)$ et du blanc $(9,8 \%)$. Une proportion importante de production s'intéresse aux couleurs jaunes et rouges soit $(66,67 \%)$.

\section{Méthode d'obtention des semences et des pépinières}

Les résultats collectés dans les quatre bassins de production montrent que les semences et les pépinières utilisées sont des tout-venants. Ainsi, elles proviennent des achats $(47,06 \%)$, de la production personnelle $(45,1 \%)$ et des dons $(7,84 \%)$. Quant aux origines des plants, (50\%) émanent des productions personnelles, $(46,88 \%)$ des achats auprès des pépiniéristes et $(3,12 \%)$ des dons (Figure 7). 


\section{Tranches d'âge des champs d'anacardes des enquêtés}

Un grand nombre de champs d'anacardes dans les zones étudiées est relativement âgé, 15 ans et plus (45\%), toute fois on retrouve des plantations qui ont moins de 5 ans preuve que la filière suscite encore un intérêt chez certains agriculteurs (Figure 8).

\section{Caractéristiques des champs d'anacardes}

La culture de l'anacarde se fait en grande partie en association avec d'autres spéculations agricoles dans les zones étudiées $(68,63 \%)$. C'est ainsi qu'on retrouve des légumineuses $(34,29 \%)$, des céréales $(31,43 \%)$, des fruitiers $(22,86 \%)$ et d'autres cultures maraichères $(11,43 \%)$ dans les parcelles d'anacardes (Figure 9). Les avantages de ces associations selon la perception paysanne, se résument à une bonne occupation de l'espace agricole, une diversification de la production, l'obtention d'un double revenu, la facilité d'entretien de la plantation d'anacardier et le bénéfice que les plants d'anacardier tirent des engrais appliqués aux cultures annuelles.

\section{Fertilisation des anacardiers}

$\mathrm{Au}$ sein des enquêtés, très peu de producteurs d'anacardes fertilisent leurs champs soit $(39,22 \%)$. Parmi les fertilisants utilisés, la fumure organique reste celle qui prédomine $(68,42 \%)$ dans ces champs (Figure 10). Cette fumure est constituée pour la plupart de la bouse de vache décomposée recueillie dans les principaux sites d'élevage. Une proportion de $60,78 \%$ n'utilise aucun fertilisant, ceci pour des raisons diverses : le manque de moyens financiers pour acheter les engrais spécifiques, l'indisponibilité en engrais spécifique, le faible niveau de connaissance des producteurs sur l'utilisation des engrais et la détermination des besoins nutritionnels de l'anacardier.

\section{Traitement phytosanitaire des plants d'anacarde}

Les traitements phytosanitaires sont pratiqués à l'ordre de 52,94\% sur les plants d'anacardes à cause des différentes attaques rencontrées, preuve que les enquêtés sont soucieux de l'entretien de leur plantation (Figure 11). Les raisons des traitements évoquées par ces producteurs sont les différentes attaques dues aux insectes ravageurs et aux maladies des anacardiers. Malheureusement, ils ne disposent pas d'un itinéraire de lutte bien définit. Pour le reste des producteurs, 9,84\% n'éprouve aucun besoin pour l'entretien de leur parcelle, 49,06\% disent n'avoir aucune maîtrise dans l'utilisation des produits phytosanitaires et $41,10 \%$ n'ont pas de moyen financier pour s'approvisionner.

\section{Périodes de récolte}

L'anacardier commence à produire des fruits dès la troisième ou la quatrième année. C'est un arbre qui peut entrer en production plusieurs fois l'an en fonction des variétés, mais surtout en fonction du climat (notamment la température et le climat) ceci dit, la grande période de production dans nos zones d'étude va du mois de janvier au mois d'avril (Figure 12), avec une abondance aux mois de février et mars.

\section{Association anacarde-coton}

Une proportion de $58,82 \%$ des enquêtés adhèrent à l'idée de pratique de la culture de l'anacarde en association avec le coton car cela pourrait leur générer un gain supplémentaire d'argent. Par ailleurs, le niveau d'association culturale avec le coton peut dépendre de plusieurs facteurs, notamment la disponibilité de terres cultivables, la densité des plantations et l'envergure des arbres. Ces raisons expliquent pourquoi $41,18 \%$ des enquêtés n'adhèrent pas à cette idée, compte tenu du problème d'ombrage évoqué par ces derniers ainsi que celui relatif au foncier (Figure 13).

\section{Acheteurs des noix}

Les noix de cajou sont à $77,14 \%$ achetées par des commerçants qui sillonnent les champs et les marchés. Par ailleurs, il est à noter que ces commerçants revendent ces noix 
à des firmes qui ne se déploient pas vraiment dans les zones de productions (Figure 14). Le circuit de vente des noix d'anacardiers n'est pas encore maîtrisé dans les différentes zones étudiées, les producteurs écoulent leurs produits en détail. Cette manière de procéder ne leur profite pas, puisque les prix ne sont pas standards.

\section{Rentabilité de la filière anacarde}

Les activités liées à la filière anacarde est rentable pour les enquêtés $(90,2 \%)$ car même si le marché des noix est encore en plein expansion, celui de la pomme d'anacarde génère pour l'instant des revenus non négligeables pour le producteur d'anacardes (Figure 15).

\section{Difficultés rencontrées par les producteurs d'anacardier}

Parmi les contraintes évoquées par les producteurs, on note un manque de soutien technique 94,12\% (Figure 16). Plus spécifiquement, on note un accès restreint aux semences $(35,29 \%)$ et aux plants $(27,45 \%)$ de bonne qualité. Autre paramètre tel que l'accessibilité aux terres a été évoqué $(37,25 \%)$.

\section{PARAMETRES DENDROMETRIQUES OBSERVES DANS LES PLANTATIONS DE QUATRE SITES ETUDIES \\ Caractéristiques dendrométriques des plantations}

Dans les zones étudiées, le diamètre au collet a varié de $0,34 \pm 0,30$ à $1,36 \pm 0,09$ $\mathrm{m}$. Elle est maximale dans la zone de Garoua (1,36 $\pm 0,28 \mathrm{~m})$. Par contre le DHP a oscillé entre $0,28 \pm 0,02$ et $1,06 \pm 0,09 \mathrm{~m}$ avec une valeur élevée enregistrée dans la zone de Garoua. La valeur la plus élevée de la hauteur a été enregistrée dans la zone de Garoua $(12,61 \pm 0,97 \mathrm{~m})$. Le test ANOVA révèle des différences très significatives $\mathrm{du}$ diamètre au collet $(\mathrm{P}=0,000)$, du DHP $(\mathrm{P}=0,000001)$ et de la hauteur $(\mathrm{P}=0,000484)$ entre les différentes zones étudiées. Aucune différence significative $(\mathrm{P}=0,249489)$ n'est observée pour le recouvrement et la largeur de feuilles $(\mathrm{P}=0,156901)$ entre les zones (Tableau 1). Par contre, significatif ( $\mathrm{P}=0,037259)$ pour la longueur des feuilles avec une valeur maximale enregistrée dans la zone de Touboro $(12,49 \pm 2,035 \mathrm{~cm})$.

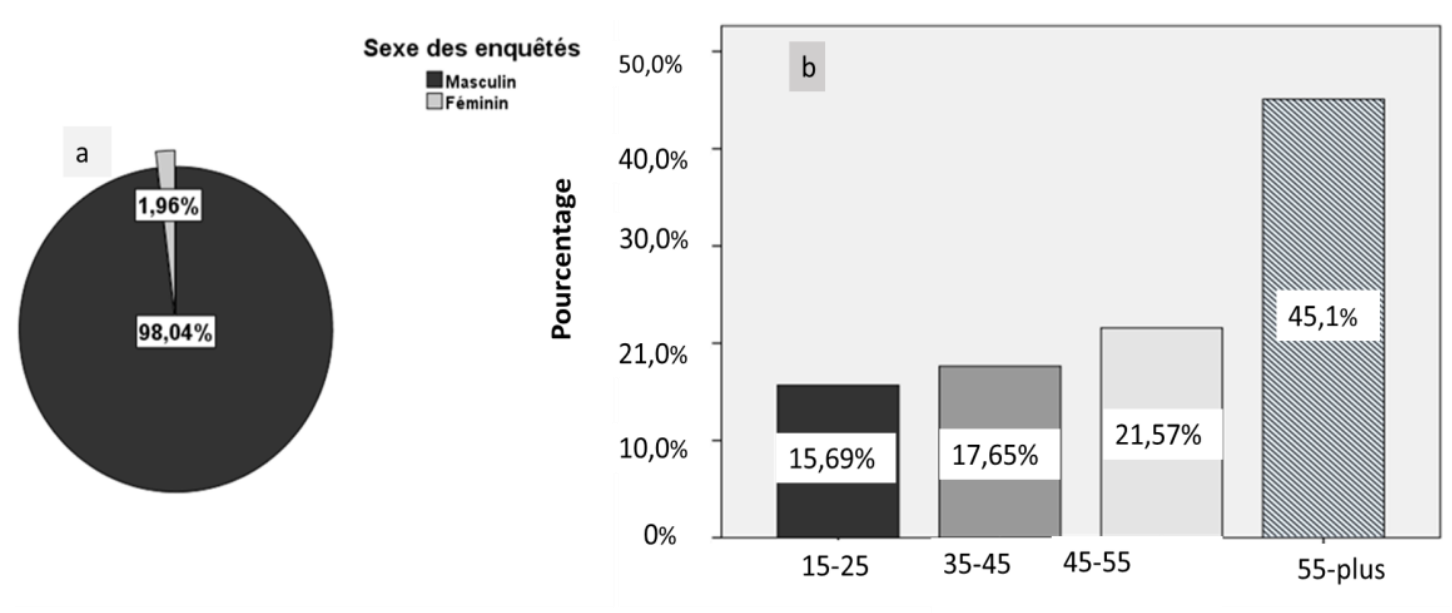

Tranche d'âge des enquêtés

Figure 2 : Genre (a) et tranches âges (b) des enquêtés. 


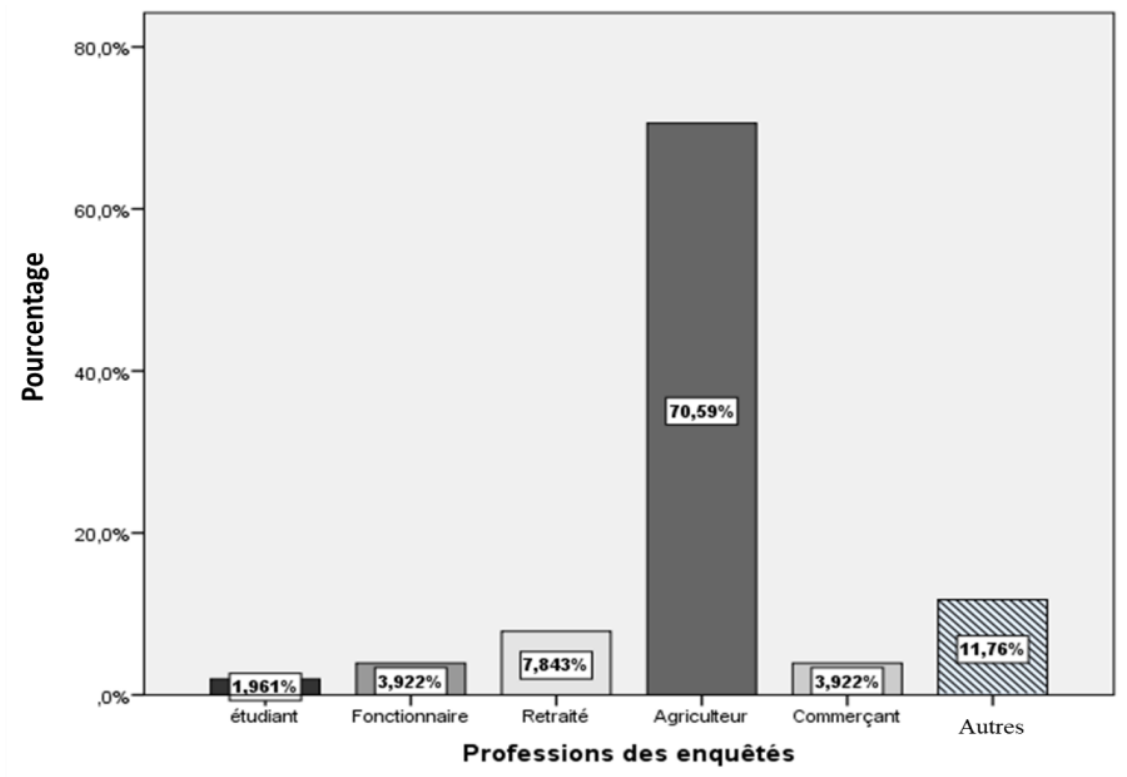

Figure 3 : Professions des enquêtées dans la zone d'étude.
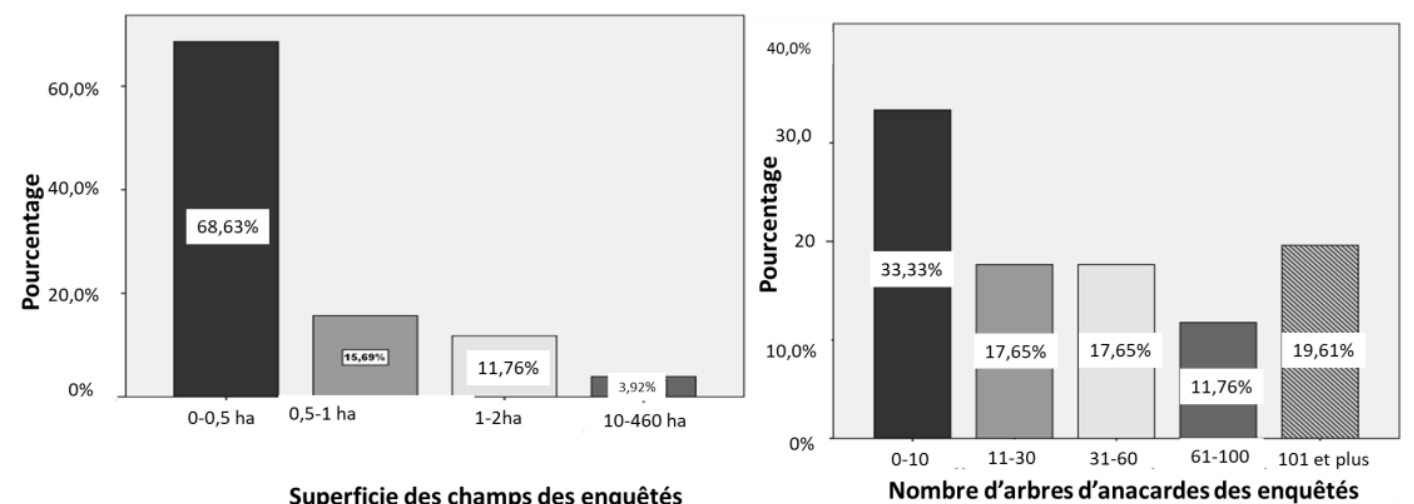

Superficie des champs des enquêtés

Figure 4 : Superficie des champs et nombre d'arbres d'anacarde des enquêtés.

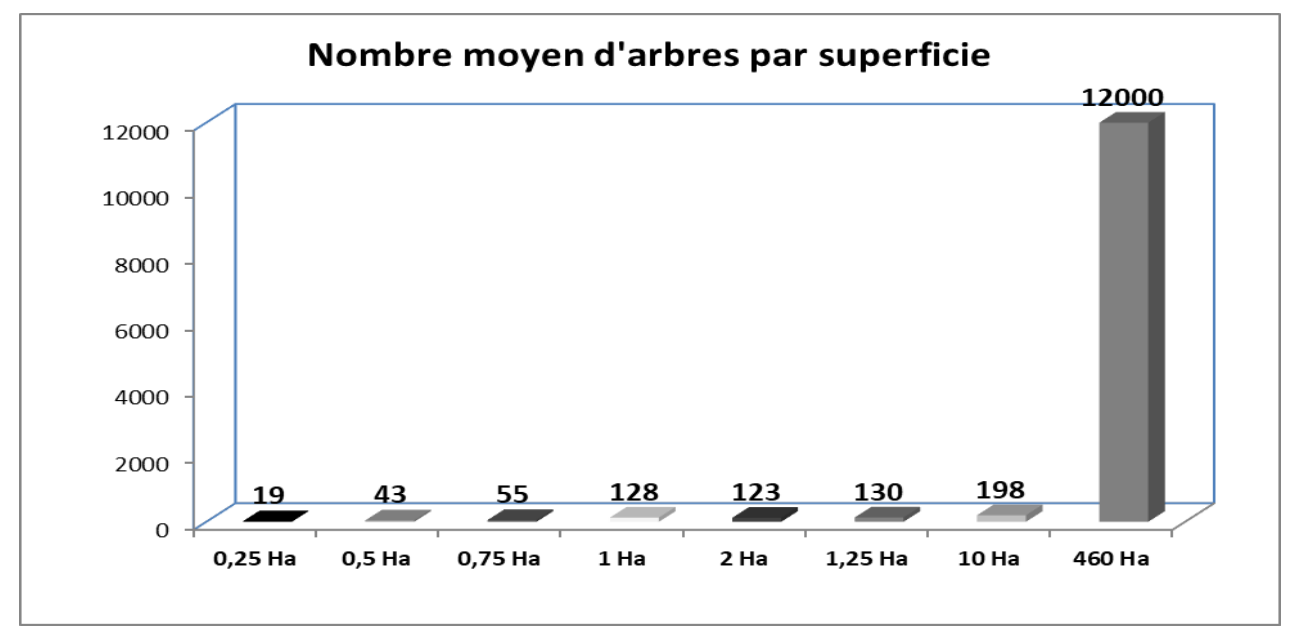

Figure 5 : Densité d'arbre dans les champs d'anacardes. 

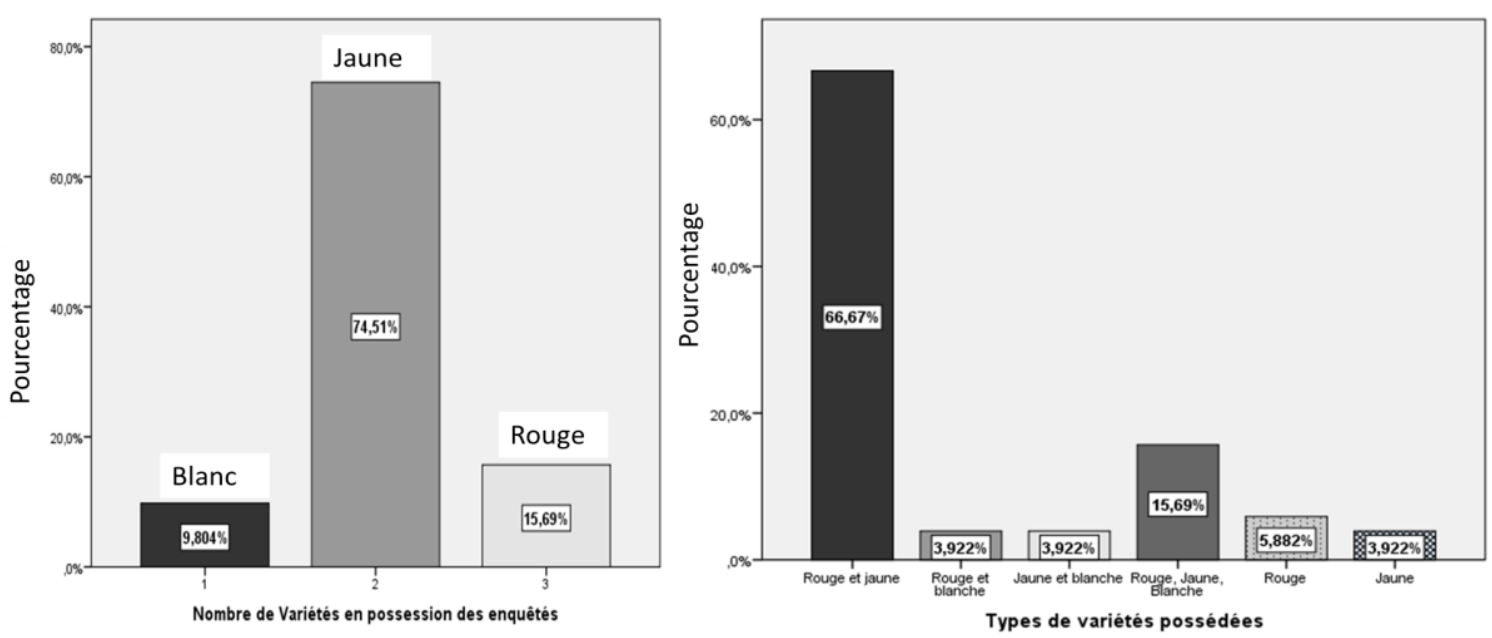

Figure 6 : Diversité des accessions observées dans les bassins de productions.
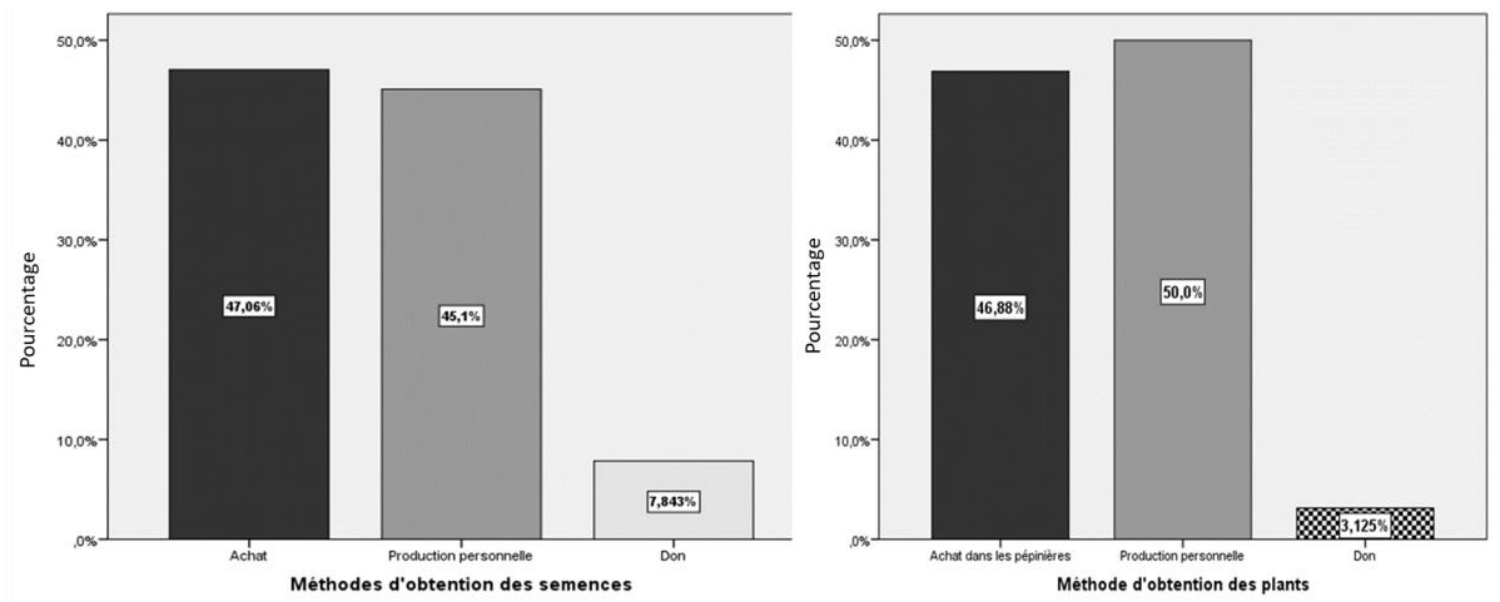

Figure 7 : Différentes méthodes d'obtention des semences et des pépinières.

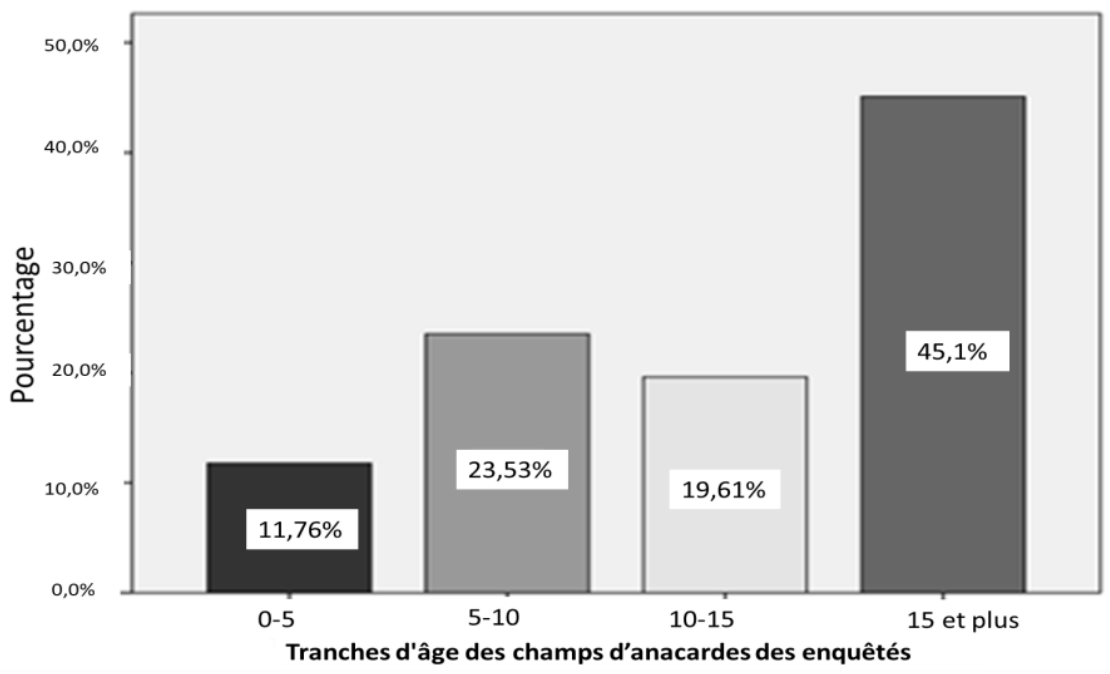

Figure 8 : Tranches d'âge des champs d'anacardes des enquêtés. 


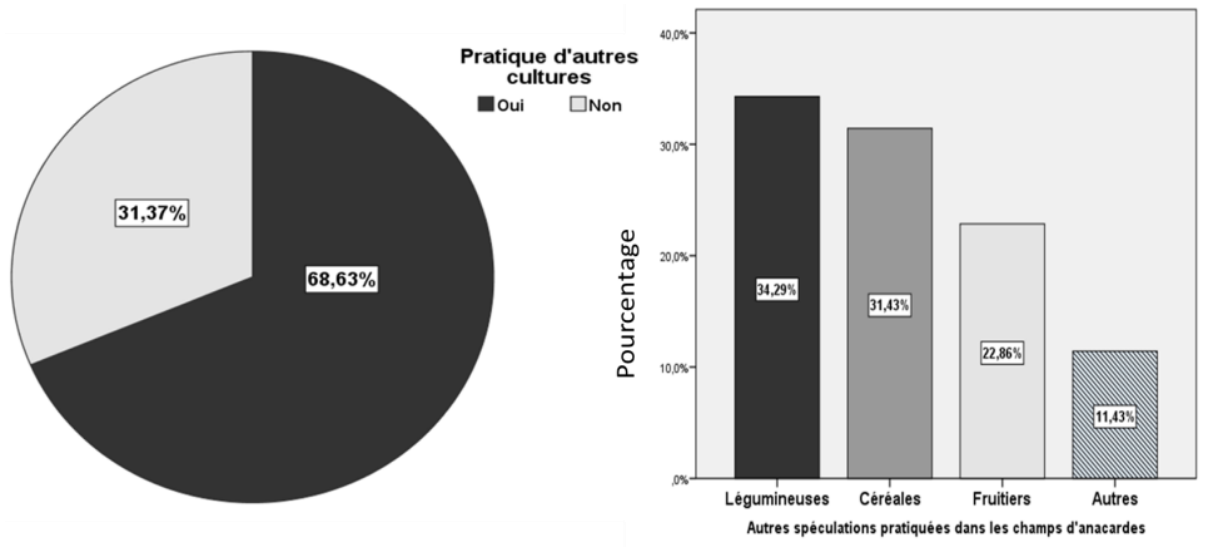

Figure 9 : Culture annuelle et pérenne associées dans les champs d'anacardiers.
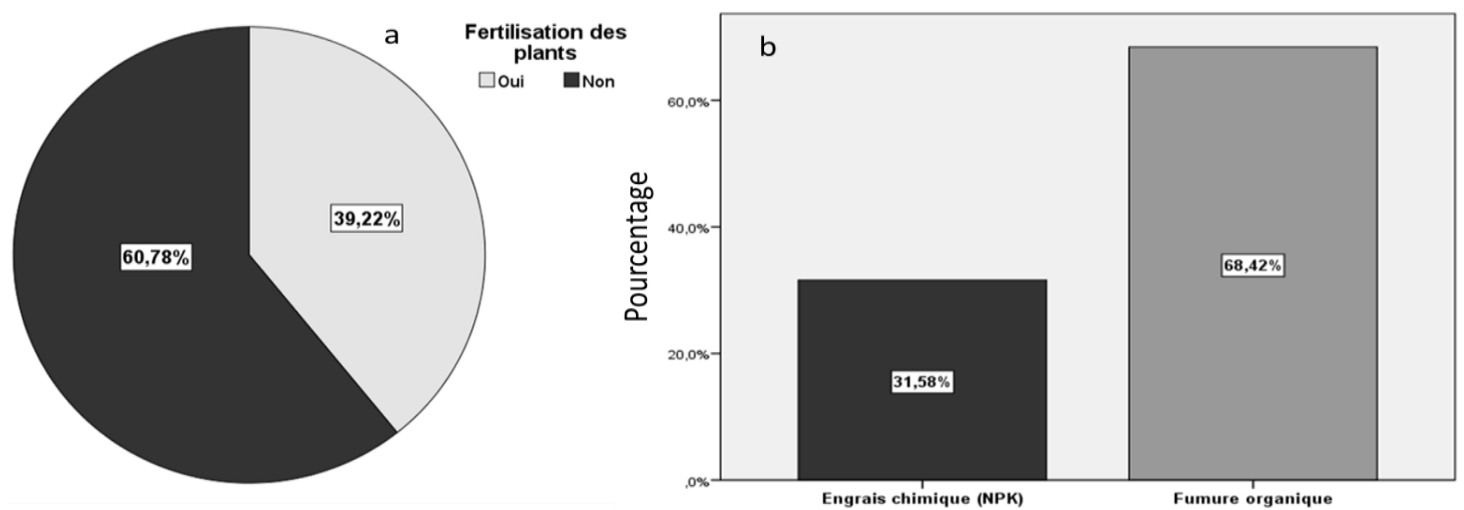

Type de fertilisants utilisés

Figure 10 : Fertilisation des anacardiers (a) et types de fertilisants utilisés (b).
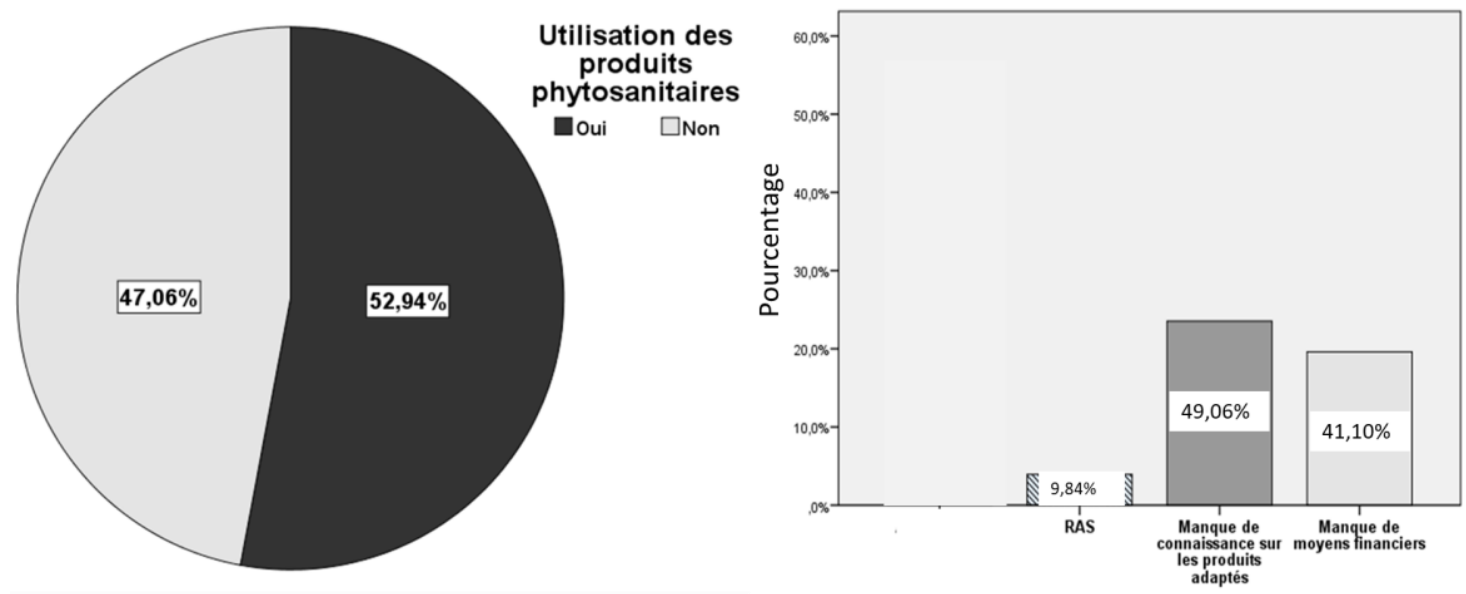

Raisons d'utilisation des produits phytosanitaires

Figure 11 : Traitement phytosanitaire des plants d'anacardes. 


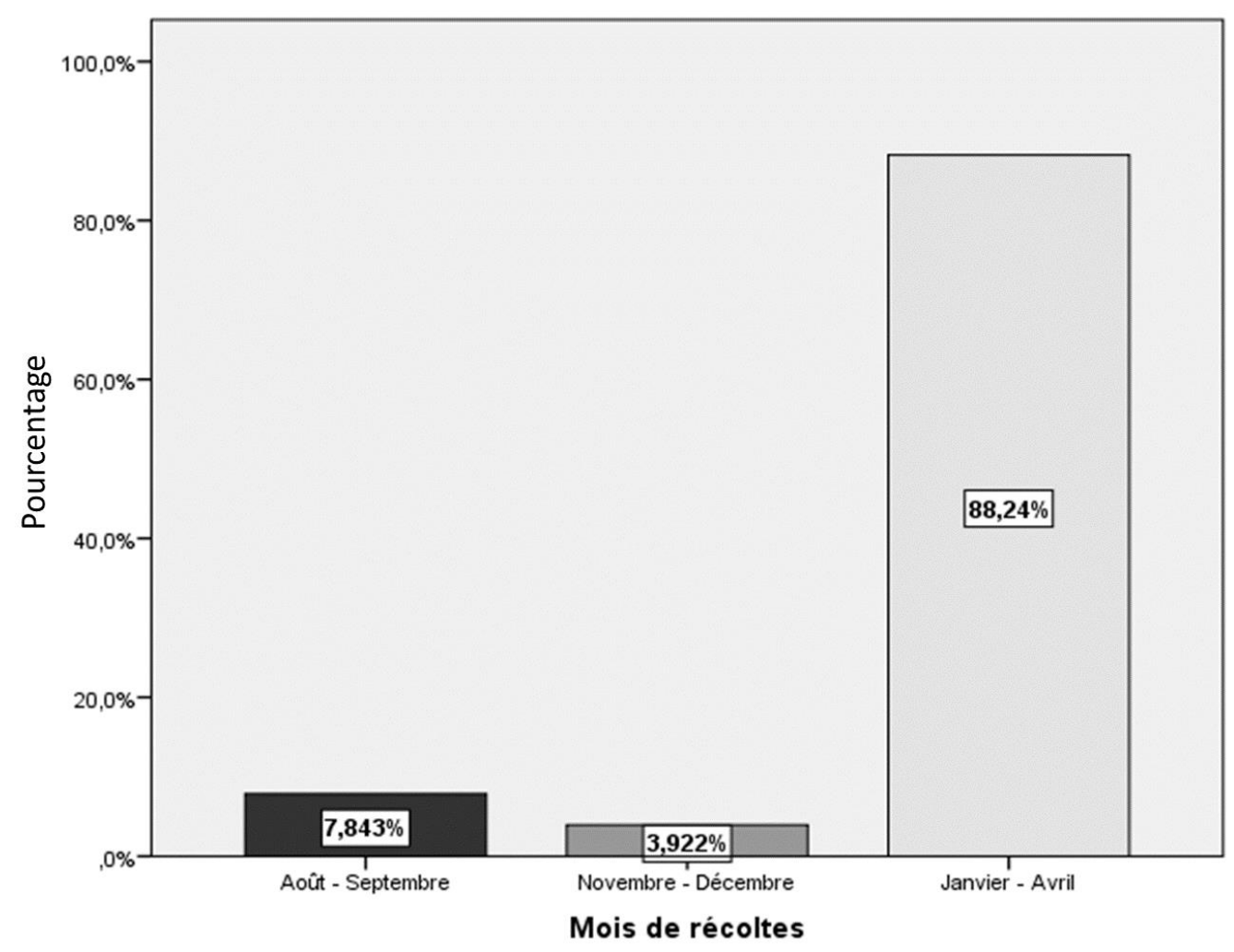

Figure 12 : Graphique représentant les périodes de récolte d'anacardier.

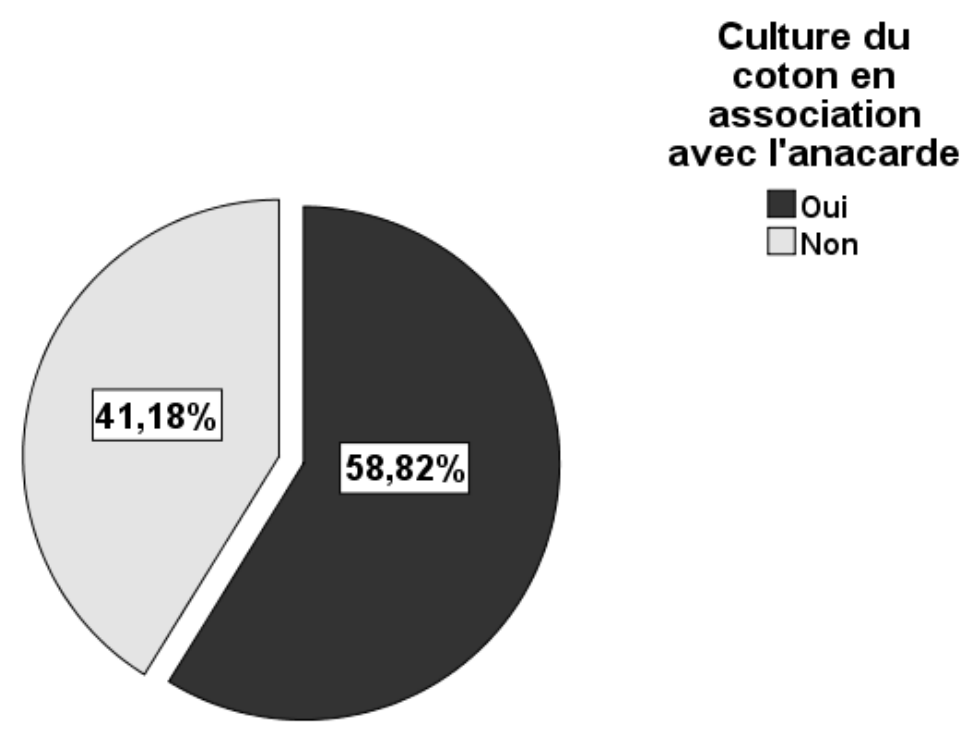

Figure 13 : Culture du coton en association avec l'anacarde. 


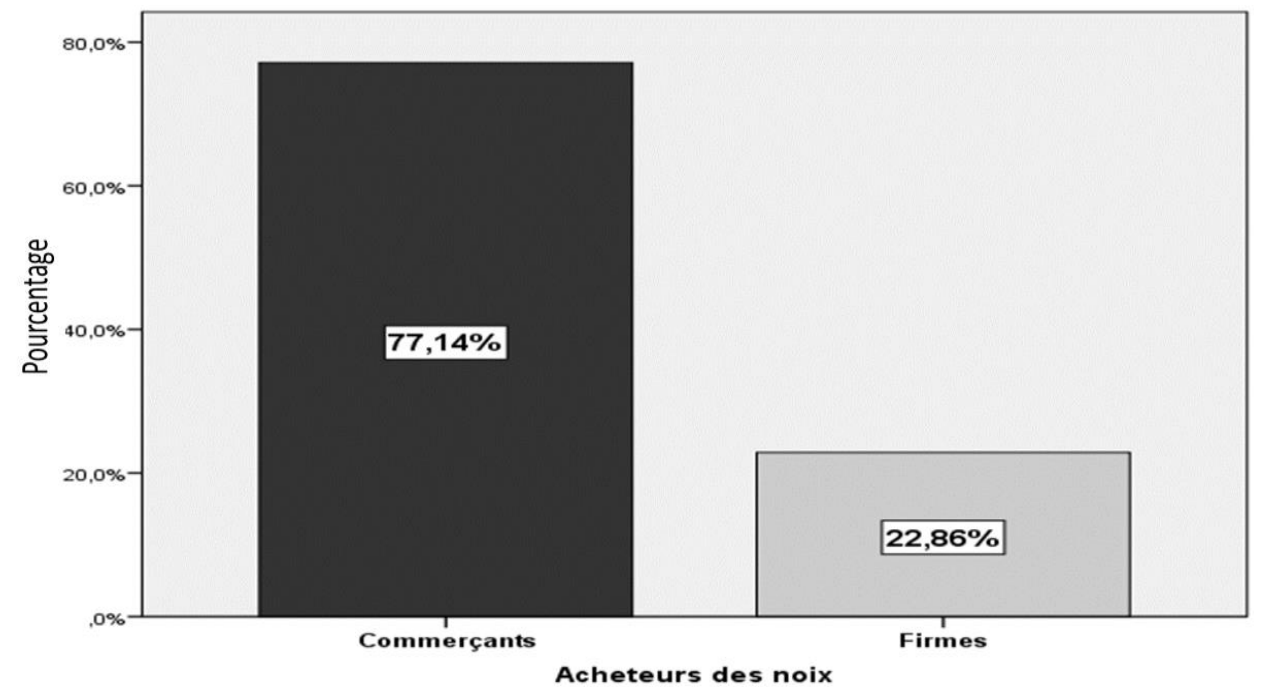

Figure 14 : Acheteurs des noix dans le circuit de commercialisation.

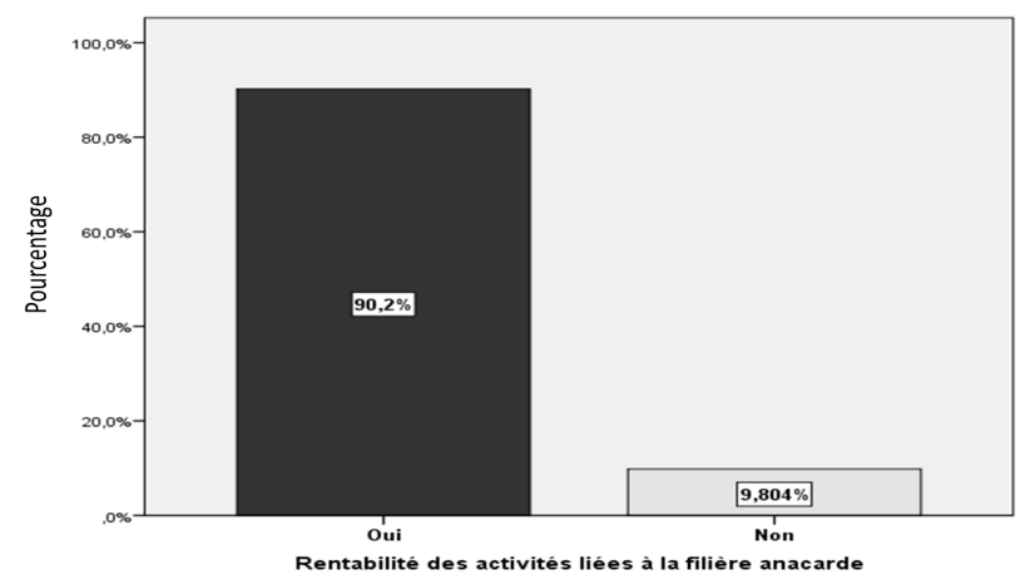

Figure 15 : Rentabilité de la filière anacarde.
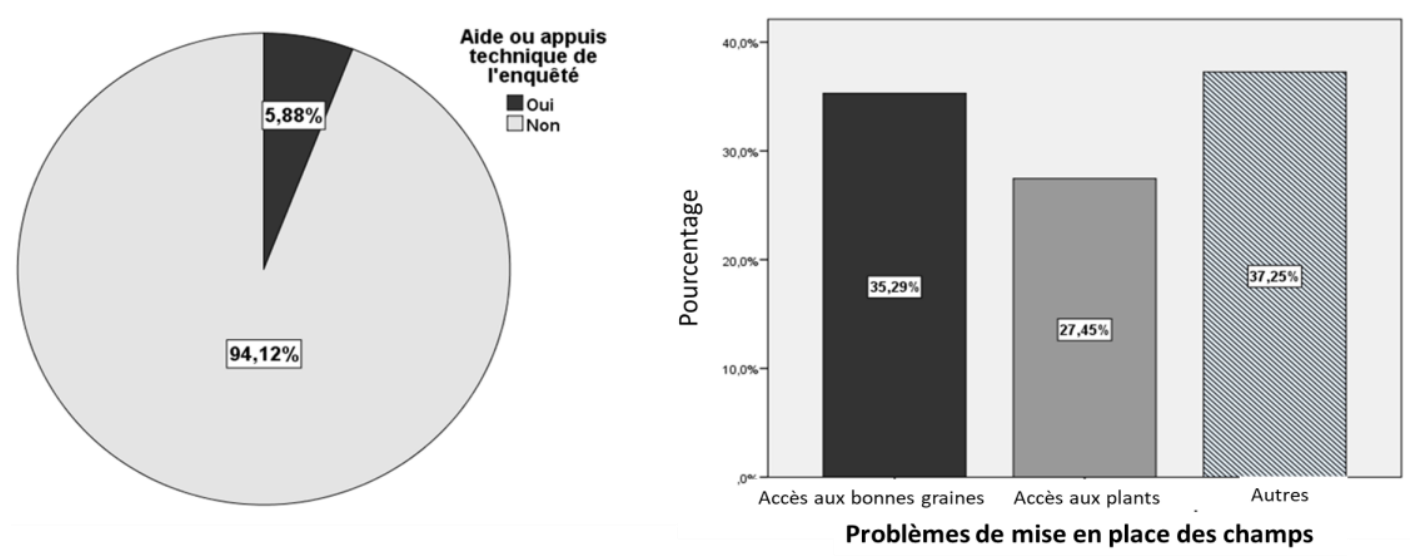

Figure 16 : Difficultés techniques liées à la production. 
Tableau 1 : Paramètres dendrométriques des anacardiers.

\begin{tabular}{lllllll}
\hline Zones & DC & DHP & Ha & Re $\left(\mathbf{m}^{2}\right)$ & LongF & LargF \\
\hline Yagoua & $0,34 \pm 0,03^{\mathrm{a}}$ & $0,28 \pm 0,02^{\mathrm{b}}$ & $7,12 \pm 1,20^{\mathrm{a}}$ & $223,94 \pm 42,61^{\mathrm{a}}$ & $12,25 \pm 0,7^{\mathrm{ab}}$ & $7,15 \pm 0,29^{\mathrm{a}}$ \\
Touboro & $0,95 \pm 0,09^{\mathrm{b}}$ & $0,79 \pm 0,10^{\mathrm{a}}$ & $6,99 \pm 0,79^{\mathrm{a}}$ & $302,56 \pm 50,46^{\mathrm{a}}$ & $12,49 \pm 0,64^{\mathrm{b}}$ & $7,11 \pm 0,34^{\mathrm{a}}$ \\
Garoua & $1,36 \pm 0,09^{\mathrm{c}}$ & $1,06 \pm 0,09^{\mathrm{a}}$ & $12,61 \pm 0,97^{\mathrm{b}}$ & $334,67 \pm 47,90^{\mathrm{a}}$ & $10,19 \pm 0,61^{\mathrm{a}}$ & $6,29 \pm 0,38^{\mathrm{a}}$ \\
Ngaoundéré & $0,93 \pm 0,04^{\mathrm{b}}$ & $0,82 \pm 0,12^{\mathrm{a}}$ & $8,99 \pm 0,71^{\mathrm{a}}$ & $309,36 \pm 49,45^{\mathrm{a}}$ & $12,19 \pm 0,58^{\mathrm{b}}$ & $7,21 \pm 0,08^{\mathrm{a}}$ \\
\hline PValue & $\mathbf{0}$ & $\mathbf{0 , 0 0 0 0 0 1}$ & $\mathbf{0 , 0 0 0 4 8 4}$ & 0,249489 & $\mathbf{0 , 0 3 7 2 5 9}$ & 0,156901 \\
\hline
\end{tabular}

Les valeurs affectées de la même lettre dans une colonne ne sont pas statistiquement différentes $(\mathrm{p}>0,05)$

DC : diamètre au collet; DHP : diamètre à hauteur de poitrine ; Ha : hauteur ; Re : recouvrement ; LongF : longueur des feuilles ; LargF : largeur des feuilles.

\section{DISCUSSION}

La forte prépondérance de l'effectif des personnes (hommes) âgées de 55 et plus, dans la création et la gestion des plantations d'anacardier pourrait s'expliquer par le manque d'intérêt des jeunes pour la plantation des essences pérennes. Cette observation a été également faite par Dieng et al. (2019) dans les grandes régions de productions d'anacarde au Sénégal. Par ailleurs, on note la non accessibilité aux terres mobilisables pour le long terme par cette couche de population ou tout simplement par le phénomène d'exode rural qui fait fuir les jeunes pour les grandes agglomérations (Tandjiékpon, 2005). La tranche d'âge majoritaire observée est proche à celle enregistrée par Lawal et al. (2010) qui ont montré que l'âge moyen des producteurs est de 56 ans au Nigéria. Ces résultats corroborent avec ceux de Samb et al. (2018) au Sénégal qui mentionne 51ans. Selon Mole (2000) repris par Ndiaye et al. (2017), les plantations d'anacarde sont en général sous le contrôle de personnes âgées entre 40 et 60 ans. La faible proportion d'implication des femmes $(1,96 \%)$ dans la culture d'anacardiers, s'expliquerait par les règles coutumières restrictives des droits fonciers sur les terres au genre féminin (Sokemawu, 2015). Parallèlement, cela pourrait constituer la cause principale du sous-effectif des planteurs femmes dans l'ensemble des quatre zones d'étude. Ces résultats corroborent ceux de Tandjiekpon (2005) qui révèlent que $(95 \%)$ des plantations sont dirigées par des hommes contre 5\% pour les femmes. Pour ce qui est des fonctions liées à cette activité, les enquêtes ont révélé qu'ils sont en majorité des agriculteurs (70,59\%), ceci témoigne de leur intérêt pour la filière. On note le travail moins contraignant que nécessite l'entretien des vergers d'anacardiers (Koffi et al., 2019). Sur cette question, Adegbola et al. (2010) ont aussi montré que l'intérêt des paysans pour l'anacardier se justifie par le revenu substantiel qu'il génère. La superficie de la production qui va de 0-0,5 ha est représentée par $(68,63 \%)$ de producteurs, seulement $(3,922 \%)$ possèdent 10 ha et plus. Ce résultat est en contradiction avec ceux de Samb et al. (2018) qui évoquent que la superficie minimale est de 1 ha dans les régions du Bassin arachidier et de la Casamance au Sénégal. Ceci traduit l'intérêt manifeste des producteurs de cette zone par rapport aux nôtres. Pour y remédier, ces trois dernières années, quelques efforts sont faits par le gouvernement camerounais (MINADER, GIZ, ANAFOR, IRAD) pour la vulgarisation paysanne et la distribution de plants aux paysans pour la création des vergers. En rapport à la diversité des accessions, trois différentes couleurs de la pomme ont été identifiées sur le terrain, à savoir : jaune, rouge et blanc. Les producteurs possèdent $75,51 \%$ de la pomme jaune. Contrairement à Wallis et al. (2016) qui ont dénombré au total quatre couleurs de la pomme. Outre les principales variétés de couleurs rouge et jaune évoqués dans notre enquête, deux autres couleurs ont été observées le jaune pâle et le rouge orangé.

En rapport à la fertilité, la majorité des producteurs fertilisent leur parcelle avec de la 
fumure organique $(68,42 \%)$, de même qu'ils sont conscients que les traitements phytosanitaires $\quad(52,94 \%) \quad$ restent indispensables pour une bonne évolution de la plantation. Nos résultats ne sont pas en phase avec ceux de Samb et al. (2018) au Sénégal, où on note une absence totale de plan de fertilisation et de traitements phytosanitaires des plantations. De même l'idée d'association de l'anacardier avec la culture du coton a été approuvée par $58,82 \%$ de producteurs, ce nouveau système de culture pourrait entrainer une transformation du paysage agricole dans le bassin cotonnier. Cependant, l'adoption de l'anacarde a aussi des impacts négatifs. Au Ghana, Evans et al. (2014) estiment que l'adoption de l'anacarde exerce une pression sur les terres familiales et risque par conséquent de compromettre l'héritage foncier des générations futures. L'étude de Diarrassouba et Koffi (2015) a montré par contre que la baisse du prix du coton-graine au kilogramme et les retards de paiement des revenus issus du coton-graine expliquent également l'adoption de l'anacarde dans les zones cotonnières. Dans les quatre zones de production d'anacarde, plusieurs jeunes plantations paysannes en association avec d'autres cultures ont été observées. Ceci pourrait s'expliquer par le fait que l'association culturale permet la diversification de la production et des sources de revenus afin de limiter les risques de mauvaise récolte liés aux aléas du climat tropical. Selon Rodrigo et al. (2001) et Opoku-Ameyaw et al. (2003), les avantages de cette pratique d'association des cultures annuelles aux arbres, peuvent inclure le contrôle des mauvaises herbes et la meilleure utilisation des ressources cultivées. En effet, l'anacardier, comme la plupart des espèces pérennes, nécessite beaucoup plus d'espace pour sa culture. Cependant, la production fruitière nécessite une densité plus faible pour un bon développement de l'espèce. La densité conditionne le partage des ressources disponibles entre les différents arbres d'une plantation et donc le niveau de concurrence interindividuel (Périé et al.,
2006). Certains auteurs comme Badiane et al. (2005) pensent que la densité optimale, tant pour le développement du houppier que pour la couverture du sol, soit de 100 arbres ha- 1 . $\mathrm{Au}$ regard des classes de densités de plantation enregistrées, allant de 19 pieds/0,25 ha à 12000 pieds/460ha, il peut être mentionné que les producteurs pratiquent de moins en moins des plantations serrées comme par le passé où l'anacardier était considéré comme une espèce forestière. Cette évolution à une densité plus lâche permet l'association de plusieurs autres cultures pérennes ou non à cette plante.

La grande période de récolte pour les producteurs est située entre les mois de janvier et avril $(88,24 \%)$. En effet, les fruits tombent de l'arbre lorsque la pomme a atteint sa pleine maturité et a pris la couleur caractéristique rouge, violet, orange ou jaune, selon la variété (Djaha et al., 2008). Cependant, les noix sont directement vendues par les producteurs aux commerçants. Contrairement aux producteurs de la préfecture de Tchamba au Togo, qui dénombrent trois niveaux d'activités commerciales. Ces trois niveaux constituent la chaîne de commercialisation qui se compose des producteurs, des acheteurs et des exportateurs (Sokemawu, 2015).

En rapport aux données dendrométriques collectées dans les zones étudiées, le diamètre au collet a varié de 0,34 $\pm 0,10$ à $1,36 \pm 0,28 \mathrm{~m}$. Cette variation pourrait s'expliquer non seulement par l'état sanitaire, physiologique et génétique des semences utilisées, mais aussi par la qualité des substrats utilisés et les soins sylvicoles (désherbage, démariage, cernage, l'arrosage, etc.) apportés aux plants. Ces résultats sont inférieurs à ceux d'Amani et al. (2015) dans les quatre peuplements de combretaceae au Niger. Le DHP a oscillé entre 0,28 $\pm 0,09$ et $1,06 \pm 0,29 \mathrm{~m}$ dans les zones étudiées. Cette variation pourrait s'expliquer par la concurrence qui s'installe entre les arbres tant aérienne (chevauchement des couronnes) que souterraine (enchevêtrement des racines dans le sol). De façon globale, on note une 
différence dans la dynamique de croissance en hauteur de l'anacardier en fonction des zones. La hauteur entre les zones étudiées varie entre $9,99 \pm 2,51 \mathrm{~m}$ à $15,61 \pm 3,06 \mathrm{~m}$. Ces résultats sont situés dans l'intervalle 7 à $20 \mathrm{~m}$ obtenus par Lacroix (2003) dans les plantations d'anacardiers du Benin. D'autres auteurs mentionnent que les hauteurs de l'anacardier comprises entre 4 et $14,5 \mathrm{~m}$ (Djaha et al., 2014). Au regard de ces données, la performance de croissance en hauteur observée dans les zones d'étude pourrait s'expliquer par les caractéristiques génétiques des souches d'anacardier introduites au Cameroun septentrional ou par une adaptabilité de ces souches aux conditions écologiques (Djaha et al., 2012) $\mathrm{du}$ pays. La valeur la plus significative de la hauteur enregistrée dans la zone de Garoua $(15,61 \pm 3,06 \mathrm{~m})$ pourrait s'expliquer par les conditions agro écologiques favorables au développement en hauteur des individus d'anacardiers issus de cette zone. Selon Djaha et al. (2014), le développement en hauteur des individus d'anacardiers peut aussi s'expliquer par les caractéristiques physiques et chimiques des sols. Le recouvrement des anacardiers dans les zones étudiées n'a pas varié. L'analyse de la dynamique de recouvrement de l'anacardier montre une tendance au développement latéral de l'espèce. Le taux de recouvrement explique le fait que la plantation influence le type mis en place par les producteurs et justifie le fait de la rareté d'associations de culture dans les plantations à anacardier et la baisse du rendement des cultures associées. Les valeurs élevées des écarts types s'expliquent par le fait qu'il y a une diversité de gestion de la structure des anacardiers. La longueur et la largeur des feuilles des anacardiers entre les zones étudiées sont semblables. C'est dire que plus il y a de l'espace autour de l'anacardier, plus le développement latéral est important (Tandjiékpon, 2005). Il est clair que la filière anacarde regorge beaucoup de potentialités pour le développement agricole du Cameroun, plus précisément dans la partie septentrionale.

\section{Conclusion}

Rendu au terme de ce travail, qui avait pour objectif d'évaluer les caractéristiques socio-économiques des producteurs d'anacarde dans le Cameroun septentrional. Il ressort que le système agroforestier basé sur l'anacardier est caractérisé par plusieurs aspects sociaux, économiques et environnementaux importants. Leur prise en compte dans l'utilisation des espaces agricoles permettra une gestion durable et efficiente des plantations paysannes existantes ou à créer. Les résultats saillants obtenus montrent que les populations productrices ou détentrices des plantations d'anacardier sont relativement âgées et que les hommes constituent l'effectif dominant des planteurs d'anacardier. Du point de vue de la dynamique de croissance des arbres d'anacardier, il a été observé que la hauteur, le diamètre de la tige et la largeur de la couronne varient d'une zone à une autre. Les densités de plantation pratiquées par les producteurs sont également variables mais sont de moins en moins fortes. En recommandations, le système agroforestier pratiqué au Cameroun septentrional pour la production de l'anacardier nécessite des améliorations pour sa durabilité. Le premier élément important à corriger est le droit d'accès aux terres cultivables pour la culture des plantes pérennes comme l'anacardier. Cet aspect permettra à toutes les couches de la communauté (jeune et vieux, homme et femme, allochtone et autochtone) de contribuer à la création et à la gestion des agroforêts à base d'anacardiers.

\section{CONFLIT D'INTERETS}

Les auteurs déclarent qu'il n'y a aucun conflit d'intérêts.

\section{CONTRIBUTIONS DES AUTEURS}

$\mathrm{BS}, \mathrm{CM}$ et AN ont mené les activités de terrain. Les résultats obtenus ont été analysés avec l'apport de AN. BS, CM et JK ont participé activement à la rédaction de ce manuscrit. 


\section{REFERENCES}

Adegbola PY, Arouna A, Adekambi SA. 2010. Estimation of the economic efficiency of cashew nut production in Benin. Rapport d'étude de PAPA/INRAB, $17 \mathrm{p}$.

Aliyu OM, Awopetu J A. 2007. Assessment of genetic diversity in three populations of cashew (Anacardium occidentale L.) using protein-isoenzyme electrophoretic analysis. Genetic Resources and Crop Evolution, 54: 1489 - 1497. DOI: 10.1007/s10722-006-9138-9

Amani A, Inoussa MM, Dan Guimbo I, Mahamane A, Saadou M, Lykke AM. 2015. Germination et croissance de quatre espèces de Combretaceae en pépinière. Tropicultura, 33(2) : 135-145. DOI :

www.tropicultura.org/text/v33n2/135

Badiane S, Sy PBA. 2005. Manuel de sylviculture de l'anacardier. Dakar, Sénégal, $30 \mathrm{p}$.

Balogoun I, Saidou A, Ahoton EL, Amadji LG, Ahohuendo CB, Adebo IB, Babatounde S, Chougourou D, Adoukonou-Sagbadja D, Ahanchede A. 2014. Caractérisation des systèmes de production à base d'anacardier dans les principales zones de culture au Bénin. Agronomie Africaine, 26 (1) : 9-22. DOI:

https://www.ajol.info/index.php/aga/104 427/94508

De figueiredo RW, Lajolo FM, Alves RE, Filgueiras HAC. 2001. Phsysicalchemical changes in early dwarf cashew pseudo fruits during development and maturation. Food Chemistry, 77 : 343 347.

DOI:

https://doi.org/10.1016/S03088146(01)00358-2.

Dedehou ESCA, Dossou J, Soumanou MM. 2015. Etude diagnostique des technologies de transformation de la pomme de cajou en jus au Bénin. International Journal of Biological and Chemical Sciences, 9(1): 371 - 387. http://ajol.info/index.php/ijbcs.
Diarrassouba D, Koffi SY. 2015. Les cultures vivrières dans une exploitation agricole à base de coton à Guiembé et Siolokaha (Korhogo, Côte d'Ivoire). Revue Échanges, 5(1): 520-539. DOI : https://www.cahiersagricultures.fr/article s/cagri/ref/2019/01/cagri.

Dieng F, Ngom D, Dia D, Sy R .2019. Efficience technique de la production d'anacarde (Anacardium occidentale $\mathrm{L}$.) dans les grandes régions de production du Sénégal. Int. J. Biol. Chem. Sci., 13 (6): 2627-2645. DOI: 10.4314/ijbcs.v13i6.16

Djaha A J-B, N'da H A, Koffi K E, Adopo A N, Ake S. 2014. Diversité morphologique des accessions d'anacardier (Anacardium occidentale L.) introduits en Côte-d'Ivoire. Rev. Ivoir. Sci. Technol., 23 : $244-258$. DOI : http://www.revist.ci

Djaha A, N'Da Adopo A, Hala N, Edo K, N'guessan A. 2008. Bien cultiver l'anacardier en Côte-d'ivoire. Direction des programmes de recherche et de l'appui au développement. 01 BP 1740 Abidjan 01, Côte d'Ivoire - Tél : (225) 23472424 - E-mail : info.sqr@cnra.ci.

Djaha JBA, N'da adopo AA, KoffI EK, Ballo CK, Coulibaly M. 2012. Croissance et aptitude au greffage de deux génotypes d'anacardier (Anacardium occidentale L.) élites utilisés comme porte-greffe en Côte d'Ivoire. Int. J. Biol. Chem. Sci., 6(4): 1453-1466. http://ajol.info/index.php/ijbcs.

Evans R, Mariwah S, Antwi KB. 2014. Cashew cultivation, access to land and food security in Brong-Ahafo Region, Ghana: Preventing the intergenerational transmission of poverty. Research Note 6, Walker Institute for Climate System Research, University of Reading. www.walker-

institute.ac.uk/publications/research_not es/.

FAO. 2014. Base des données de la FAO 2011, http://faostat3.fao.org 
Hamawa Y, Dona A, KAnmegne ON, Mbaye C, Niwah, Awono JMDK, Mapongmetsem PM. 2019.Effet du poids de noix et de la dose d'engrais sur la germination et la croissance de l'anacardier (Anacardium occidentale L., Anacardiaceae) dans la savane guinéenne du Cameroun. Afrique Science, 15(5): $\quad 302-312$. http://www.afriquescience.net

Koffi SY, Oura KR. 2019. Les facteurs de l'adoption de l'anacarde dans le bassin cotonnier de Côte d'Ivoire. Cah. Agric., 10: 28-24. DOI: https://doi.org/10.1051/cagri/2019025

Kouassi EKA. 2018. Contribution à la valorisation des sous-produits agricoles en bioproduits, Thèse de doctorat de l'Université de Toulouse, (2018) 169 p.

Lacroix E. 2003. Les anacardiers, les noix de cajou et la filière Anacarde à Bassila et au Bénin. Projet Restauration des Ressources Forestières de Bassila, GTZ, République du Bénin, 75 p.

Lautié E, Dorniera M, de Souza Filhoc M, Reynes M. 2001. Les produits de l'anacardier : caractéristiques, voies de valorisation et marchés. Fruits., 56 (4): 235-248.

DOI: https://doi.org/10.1051/fruits:2001126

Lawal JO, Oduwole OO, Shittu T R, Muyiwa AA.2010. Profitability of value addition to cashew farming households in Nigeria. Afr. Crop Sci. J., 19 : 49 - 54. DOI : 10.15666/aeer/1604_46554665

Manetsa V. 2011. Etude multi-échelles des précipitations et du couvert végétal au Cameroun : analyses spatiales, tendances temporelles, facteurs climatiques et anthropiques de variabilité du NDVI. Sciences de la Terre. Université de Bourgogne. 14p.

Marlos BA, Claudivan F, lacerda DE, Enéas gomes F, Carlos de abreu B, José Prisco T .2007. Physiology of cashew plants grown under adverse conditions. Brazilian Journal of Plant Physiology, 19 (4): 449-461. DOI: 10.1590/S167704202007000400012
Mole PN. 2000. Smallholder cashew development opportunities and linkages to food security in Nampula Province, Mozambique: Summary of findings and implications for Agronomie Africaine. Food Security Collaborative Working Papers 56043, Michigan State University, Department of Agricultural, Food, and Resource Economics.

Ndiaye S, Charahabil MM, Diatta M. 2017. Caractérisation des Plantations à base d'anacardier (Anacardium occidentale L.) dans le Balantacounda: cas des communes de Kaour, Goudomp et Djibanar (Casamance/Sénégal). European Scientific Journal., 13 : 242257.

DOI: 10.19044/esj.2017.v13n12p242

Ndong TA, Ndiaye O, Sagna MB, DiallO A, Galop D, Guisse A. 2015. Caractérisation de la végétation ligneuse sahélienne du Sénégal : cas du Ferlo. Int. J. Biol. Chem. Sci., 9(6): 2582-2594. http://ajol.info/index.php/ijbcs

Olossoumaï F, Agbodja FAC. 2001. Plantation d'anacardier (Anacardium occidentale) : production et commercialisation de noix cajou a igbomakro dans la sous-préfecture de Bassila. Mémoire- Projet de fin de cycle pour l'obtention du Diplôme d'Etudes Agricoles Tropicales (DEAT).

Opoku-Ameyaw K, Oppong FK, OffriFrimpong K, Amoah FM, Osei-Bonsu K. 2003. Intercropping robusta coffea with some edible crops in Ghana: agronomic performance and economic returns Ghana. J. Agri. Sci., $36: 13$ - 21. DOI : https://link.springer.com/article/10.1007/ s10457-007-9058-5

Périé C, Ouimet R, Duchesne L. 2006. Evolution Contemporaine des principales caractéristiques dendrométriques des stations du RESEF. Mémoire de recherche forestière $\mathrm{n}^{\circ} 149 . \mathrm{Pp} 35$.

Rodrigo VHL, Stirling CM, Teklehaimanot Z, Nugawela A. 2001. Intercropping with banana to improve fractional interception and radiation use efficiency of immature 
rubber plantations. Field Crops Resources., 69(3): 237 - 249. DOI: 10.1016/S0378-4290(00)00147-7

Samb SO, Touré MA, Faye Elhadji Ba HS, Diallo AM, Badiane S, Sanogo D. 2018. Caractéristiques sociodémographique, structurale et agronomique des plantations d'anacardier (Anacardium occidentale L.) du Bassin arachidier et de la Casamance / Sénégal. Journal of Animal \& Plant Sciences, 3: 6307-6325. http://www.m.elewa.org/JAPS.

Sokemawu K. 2015. Le Développement de la filière anacarde dans la préfecture de Tchamba au Togo : vers une nouvelle stratégie paysanne de diversification des revenus agricoles. Revue de Géographie de l'Université de Ouagadougou, 2(4): $22 \mathrm{p}$.

Soro D. 2012. Couplage de procédés membranaires pour la clarification et la concentration du jus de pomme de cajou : performances et impacts sur la qualité des produits, Thèse de doctorat, Université de Montpellier Sup Agro, $156 \mathrm{p}$.
Tandjiékpon AM. 2005. Caractérisation du système agro forestier à base d'anacardier (Anacardium occidentale L.) en zone de savane au Bénin. Mémoire pour l'obtention du Diplôme d'Étude Approfondie (DEA), Faculté des Lettres, Arts et Sciences Humaines, Université d'Abomey-Calavi, Bénin. 104 p.

Trevian MTS, Pfundstein B, Haubner R, Würtele G, Spiegelhalder B, Bartsch H, Owen RW. 2005. Caracterisation of alkyl phenols in cashew (Anacardium occidentale L.) products and assay of their antioxidant capacity. Food and Chemical Toxicology, 44: 188 - 197. www.elsevier.com/locate/foodchemtox.

Wallis NZ, Bagnan MA, Akossou AYJ, Kanlindogbe CB. 2016. Caractérisation morphologique d'une collection de fruits d'anacardier provenant de la commune de Parakou (Bénin). Int. J. Biol. Chem. Sci., $\quad$ 10(6): 2413-2422. http://ajol.info/index.php/ijbcs. 